\title{
ANALYSIS OF HIGH FREQUENCY BREAKING WAVES AND LOW FREQUENCY SURGES GENERATED IN HARBORS DUE TO PASSAGE OF DEEP-DRAFT TANKERS
}

\author{
Arpit Agarwal, Mott MacDonald, arpit.agarwal@mottmac.com \\ Scott Fenical, Mott MacDonald, scott.fenical@mottmac.com \\ Kirsten McElhinney, Mott MacDonald, kirsten.mcelhinney@mottmac.com \\ Paul Carangelo, Port of Corpus Christi Authority, paul@pocca.com \\ David Krams, Port of Corpus Christi Authority, krams@pocca.com
}

\begin{abstract}
Cline's Point Marina, located in Port Aransas, TX, has been experiencing detrimental conditions near the marina's entrance and within the marina itself during the passage of deep-draft ship traffic. The wave activity is primarily generated by pressure field effects from large, laden outbound vessels in Corpus Christi Ship Channel (CCSC). The basin was originally protected by an approximately $180 \mathrm{ft}$. long breakwater constructed in 1976 on the west side of the entrance which by 1980 has deteriorated and partially failed to $120 \mathrm{ft}$. long breakwater and continued deteriorating over time, reaching its approximate $60 \mathrm{ft}$. long current condition by 2003 . The deterioration of this breakwater has reportedly resulted in enhanced penetration of deep-draft vessel wave activity into the marina (Figure 1). Mott MacDonald (MM) evaluated the mechanisms by which waves are generated in the navigation channel, transform, and enter the harbor, quantified the level of protection afforded by past and present entrance breakwater configuration(s), and developed conceptual alternatives for improving conditions inside the marina.
\end{abstract}

Deep-draft vessel-induced surge analysis was performed to evaluate water level fluctuations and surge-induced current velocities inside the marina generated by passing vessels using the Vessel Hydrodynamics Longwave Unsteady (VH-LU). The VHLU modeling system (Fenical et al 2006) is a comprehensive hydrodynamic modeling system that calculates water level and current velocity fluctuations generated by moving deep-draft vessels. Site observations and modeling of existing harbor conditions indicated that the pressure field effects change significantly at higher passing speeds (e.g. 10 knots, vs. 6 knots). At higher speeds, along with the longer-period (150-250 sec) water level fluctuations, additional shorter-period wave components are observed that manifest themselves as breaking waves. However, as site observations and model results indicate, these shorter-period waves are much longer in duration than expected for typical vessel wakes, with behavior similar to waves with periods in the range 1020 seconds. Figure 2 shows water level time histories predicted for three different passing speeds, and the shorter-period wave components riding on top of the longer-period water level fluctuations.

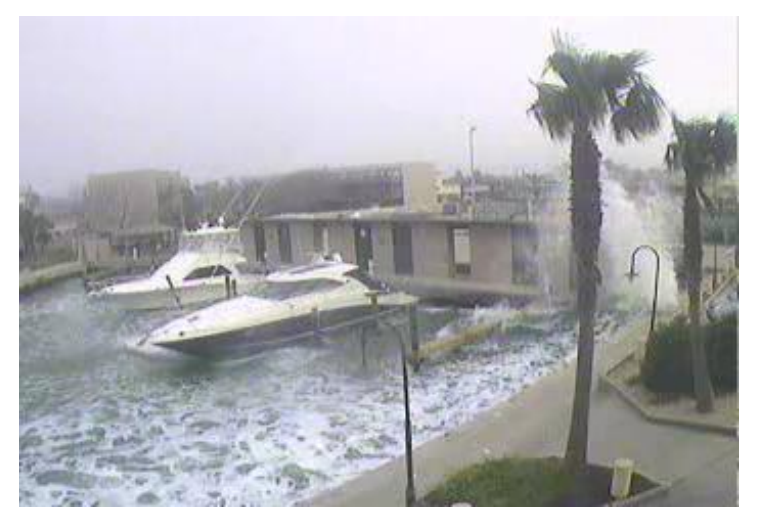

Figure 1 - Tanker Induced Breaking Wave Inside Harbor

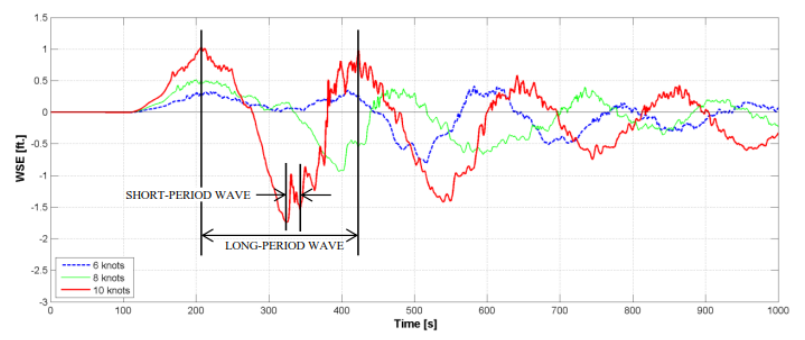

Figure 2 - Modeled water level time series for different passing vessel speeds.

Spatial plots for the shorter-period breaking waves were created by isolating the higher-frequency component of the waves from the overall water level time series using spectral analysis (Fast Fourier Transform routines). This analysis was performed at locations with $2 \mathrm{~m}$ resolution within the harbor, and a representative wave height was computed for each component (longer-period or shorter-period). Maps were generated for each, allowing evaluation of alternatives performance in reducing either component. While preferable to reduce both the long-period and short-period wave components to improve conditions inside the marina, the short-period waves have the potential to cause greater damage to the berthed vessels than the long-period surge waves as long as sufficient underkeel clearance is maintained in the marina. Alternatives were developed and analyzed for reducing the penetration of both the long-period water level oscillations and shorter-period breaking waves into the marina.

\section{REFERENCES}

Fenical, S., Kolomiets, P., Kivva, S. and Zheleznyak, M. 2006. "Numerical Modeling of Passing Vessel Impacts on Berthed Vessels and Shoreline", ICCE 2006. 